\title{
First experience with single incision laparoscopic surgery in Slovakia: Concomitant cholecystectomy and splenectomy in an 11-year-old girl with hereditary spherocytosis
}

\author{
Vladimir Cingela\#, Lenka Zabojnikova ${ }^{a \#}$, Patricia Kurucova ${ }^{b}$, Ivan Vargac
}

\begin{abstract}
Aims. Hereditary spherocytosis is an autosomal dominant inheritance disorder of the red blood cell membrane characterized by the presence of spherical-shaped erythrocytes (spherocytes) in the peripheral blood. The main clinical features include haemolytic anemia, variable jaundice, splenomegaly and cholelithiasis caused by hyperbilirubinemia from erythrocyte hemolysis. Splenectomy does not solve the congenital genetic defect but it stops pathological hemolysis in the enlarged spleen. If gallstones are present, it is appropriate to perform cholecystectomy at the time of splenectomy, although the patient has symptoms of gall bladder disease. We present the case of single incision laparoscopic surgical (SILS) concomitant splenectomy and cholecystectomy performed with conventional laparoscopic instruments in an 11-year-old girl with the diagnosis of hereditary spherocytosis.
\end{abstract}

Methods. A $2-3 \mathrm{~cm}$ umbilical incision was used for the placement of two $5 \mathrm{~mm}$ trocars and one $10 \mathrm{~mm}$ flexible videoscope. Conventional laparoscopic dissector, grasper, Ligasure, Harmonic Ace and hemoclips were the main tools during surgical procedure. We prefer Single Incision Laparoscopic Surgery Foam Port (Covidien) as the single umbilical device for introduction into the abdominal cavity. First, we performed cholecystectomy, then the gallbladder was put aside over the liver and after that we peformed splenectomy. To remove the detached spleen and gallbladder, a nylon extraction bag is introduced through one of the port sites. The spleen is than morcellated in the bag with forceps and removed in fragments. After that we removed them and the umbilical fascial incision was closed.

Result. Splenectomy is the only effective therapy for this disorder and often it is performed in combination with cholecystectomy. Conventional surgery requires a wide upper abdominal incision for correct exposure of the gallbladder and spleen. Our experience shows that SILS splenectomy and cholecystectomy is feasible even in young children and despite the small number of cases in the world, we consider the combined laparoscopic approach safe and effective for the treatment of hereditary spherocytosis.

Conclusion. According to actually published guidelines, the laparoscopic approach to concomitant splenectomy and cholecystectomy is recommended, but it depends on the availability of appropriately trained surgeons and suitable equipment.

Key words: single incision laparoscopic surgery, hereditary spherocytosis, splenectomy, cholecystectomy

Received: February 22, 2013; Accepted: July 24, 2013; Available online: September 4, 2013

http://dx.doi.org/10.5507/bp.2013.058

${ }^{a}$ Department of Pediatric Surgery, Faculty of Medicine and Children's Medical Hospital, Comenius University in Bratislava, Limbova 1, 833 40 Bratislava, Slovak Republic

${ }^{b}$ Department of Pediatric Anaesthesiology and Intensive Medicine, Children's Medical Hospital, Limbova 1, 83340 Bratislava, Slovak Republic cInstitute of Histology and Embryology, Faculty of Medicine, Comenius University in Bratislava, Sasinkova 4, 81108 Bratislava, Slovak Republic

${ }^{\#}$ Authors contributed equally to the work

Corresponding author: Lenka Zabojnikova, e-mail:zabojnikova.lenka@gmail.com

\section{INTRODUCTION}

Hereditary spherocytosis (HS) refers to a group of heterogeneous inherited anemia that is characterized by the presence of spherical-shaped erythrocytes called spherocytes, on the peripheral blood smear. The abnormal morphology and shorter lifespan of the erythrocytes in HS are attributable to a deficiency or dysfunction in one or more of the proteins that compose the red blood cell membrane cytoskeleton whose role is to maintain the shape, deformability and elasticity of the erythrocyte ${ }^{1,2}$. Hereditary spherocytosis is the most common congenital hemolytic anemia in Caucasians, with an estimated prevalence ranging from 1:2000 to 1:5000. Approximately $75 \%$ of cases display an autosomal dominant pattern of inheritance, the remaining comprise recessive forms and de novo mutations ${ }^{3}$. The main clinical features of hereditary spherocytosis are haemolytic anaemia, variable jaundice, splenomegaly and premature cholelithiasis. Although the diagnosis of HS is often made in childhood and young adulthood, it may be diagnosed at any time of life including old age ${ }^{46}$.

The two most often affected organs by HS are the spleen and gallbladder. With regard to its structure and function, the spleen is considered as two separate organs. The white pulp of the spleen is an important part of the 
immune system, whereas the red pulp is connected to the bloodstream and is engaged in phagocytosis of senescent, damaged, or genetically altered (e.g. hereditary spherocytosis) red blood cells. The extraordinarily splenic blood microcirculation is basic for red pulp's very sensitive blood purge. Some of arterioles and arterial capillaries end blindly while the blood freely flows out into the three-dimensional network of connective tissue splenic cords of Billroth, with numerous macrophages. The blood elements with undisturbed elasticity of cell membrane subsequently return to the blood circulation by penetrating through the small openings in the walls of specialized capillaries (splenic venous sinuses) (ref. ${ }^{7-10}$ ). The altered erythrocytes in hereditary spherocytosis are vulnerable to splenic sequestration and subsequent lysis and cause the characteristics of this disease such as jaundice, anemia, splenomegaly, and cholelithiasis. According to actually published guidelines, the laparoscopic approach to splenectomy is recommended, but this is dependent on the availability of appropriately trained surgeons, and suitable equipment. New guidelines also recommend, when splenectomy is indicated in children, ideally it should be done after the age of $\operatorname{six}^{11}$.

In HS is a high incidence of pigmented gallstones among patients with spherocytosis, similar to other hemolytic anemias. Cholelithiasis is caused by hyperbilirubinemia from erythrocyte hemolysis and affects $50 \%$ of unsplenectomized patients who have hereditary spherocytosis. Splenectomy alone is sufficient treatment in the absence of gallstones. If gallstones are present, it is appropriate to perform cholecystectomy at the time of splenectomy, although if the patient has symptoms of gall bladder disease, most surgeons will remove the gall bladder at the same time as the splenectomy ${ }^{6,12}$. According to Guidelines for the diagnosis and management of hereditary spherocytosis - 2011 update, when stones are incidental findings without symptoms, the value of cholecystectomy remains controversial $^{11}$. As per our experience, single incision laparoscopic surgery (SILS) can be used effectively to perform simultaneous splenectomy and cholecystectomy in patients with hereditary spherocytosis ${ }^{13}$.

In this article we present our experience with an 11-year-old girl who underwent combined SILS splenectomy and cholecystectomy for hereditary spherocytosis with positive family history, splenomegaly and cholelitihiasis.

\section{Patient}

The preoperative diagnosis and indications for splenectomy in our patient, an 11-year-old girl, were established by a pediatric hematologist. The patient received preoperative vaccination with polyvalent pneumococcal, meningococcal and Haemophilus influenza vaccines. In this case gallstones were present on ultrasonography, so it was appropriate to perform cholecystectomy at the time of splenectomy which was indicated at the Department of Pediatric Surgery of the Children's Medical Hospital in Bratislava, Slovakia.

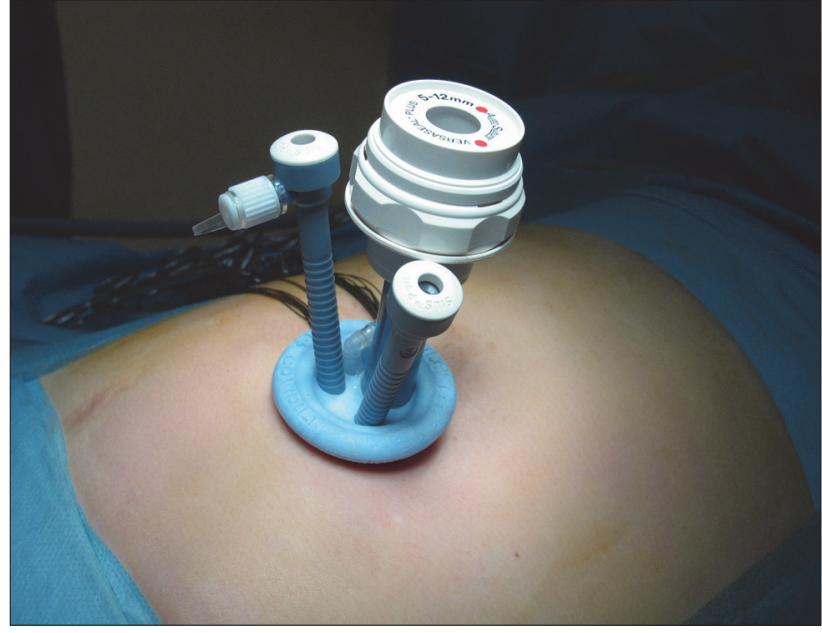

Fig. 1. Blue single incision laparoscopic surgery foam port (Covidien).

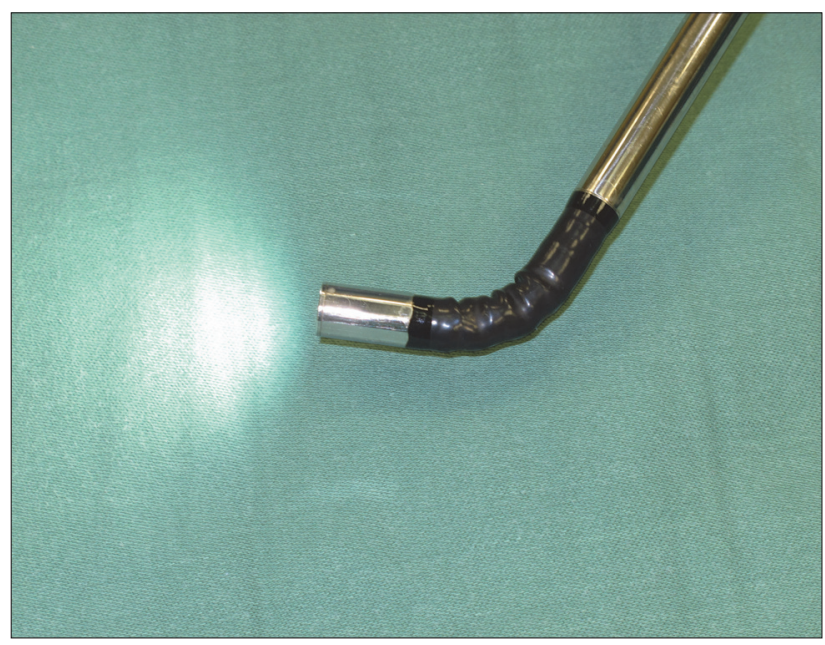

Fig. 2. Flexible videoscope, diameter $=10 \mathrm{~mm}$.

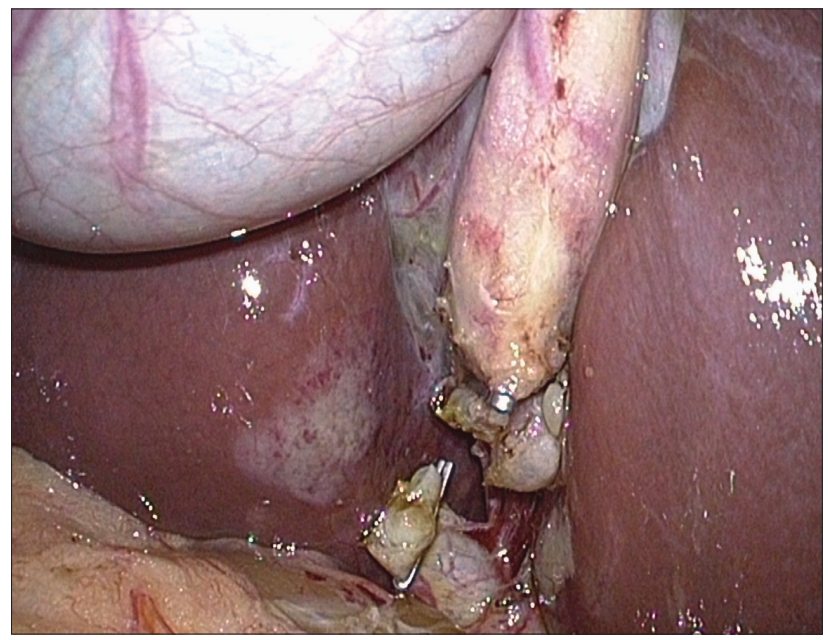

Fig. 3. Clipping and dividing of cystic duct. 


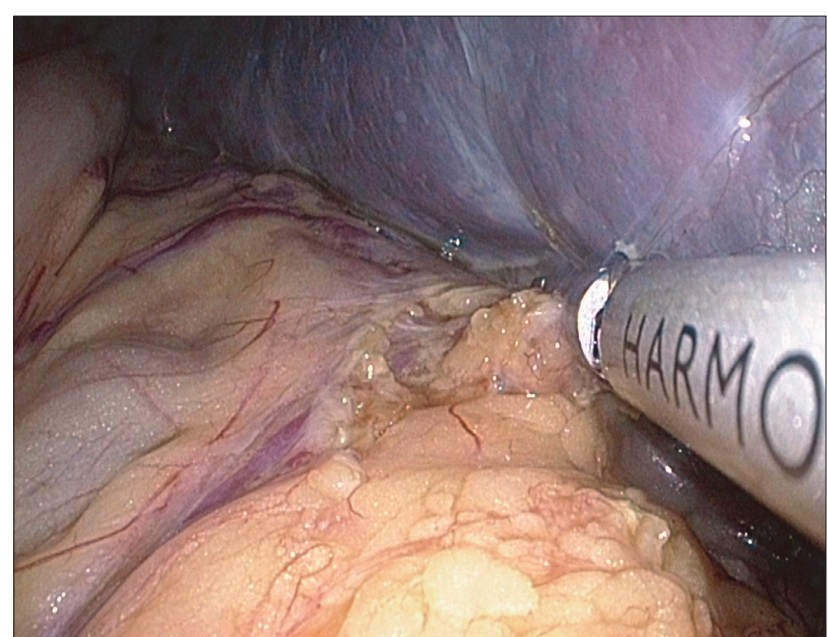

Fig. 4. Dissection of the distal polar vessels with Harmonic scalpel.

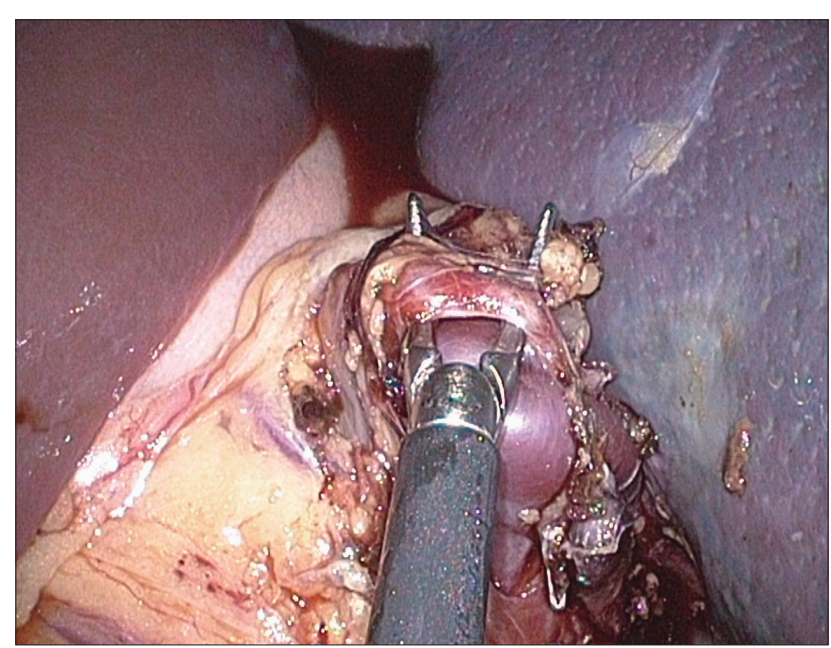

Fig. 5. If the artery is first divided, spleen size and tissue turgor may decrease in important ways and make splenectomy easier.

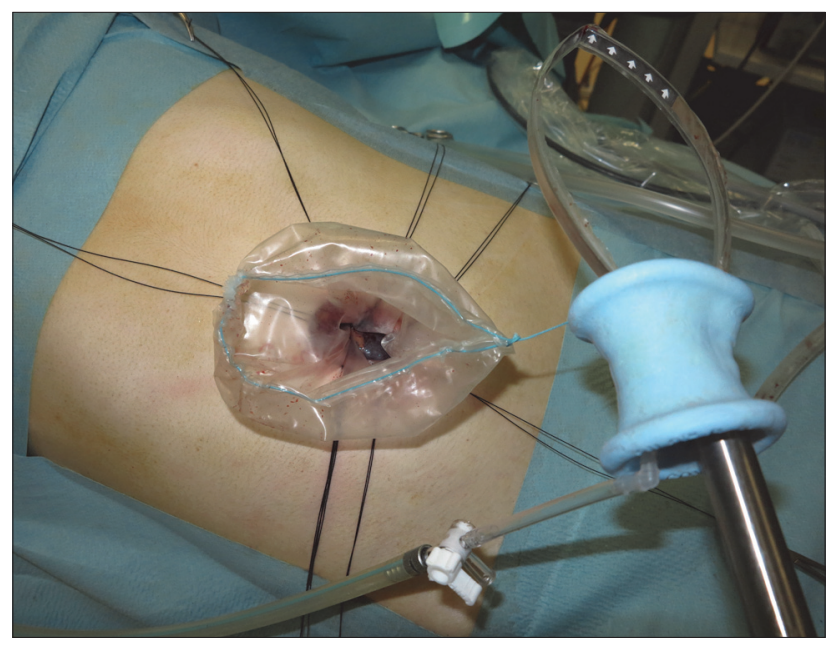

Fig. 6. Finally removing of both organs with using an endobag.

\section{Instruments}

The advent of newer laparoscopic trocars and instruments allow us to perform scarless surgery. All instruments enter the abdominal cavity through a single incision (Fig.1). There is just one incision within the belly button, which leads to less pain and improved cosmetic outcome. Available instruments can be articulating, curve-shaped, or conventional rigid laparoscopic devices. Instruments which are roticulating and provide several degrees of freedom help us to overcome the main problem -triangulation reduction tools and allow us to perform these operations rather than the standard 3 or 4 incision laparoscopy. In this case, the SILS splenectomy and cholecystectomy was performed with conventional laparoscopic instruments. A 2 - $3 \mathrm{~cm}$ umbilical incision was used for the placement of two $(5 \mathrm{~mm})$ trocars and one $(10-\mathrm{mm})$ flexible videoscope (Fig. 2). Conventional laparoscopic dissector, grasper, Ligasure and Harmonic Ace were the main tools during our surgical procedure.

\section{Technique of creation of pneumoperitoneum}

SILS concomitant splenectomy and cholecystectomy was performed by two attending surgeons. Patient underwent general endotracheal anesthesia. The patient was placed in a supine - frog position. The main surgeon usually stands between the patient's legs, which offer a more ergonomical approach. The basic surgical steps for a SILS are similar to the standard laparoscopic approach. The essential differences are in the way we enter the abdominal cavity, the location of SILS port and laparoscopic instruments, which are used. The umbilicus is the anatomic area for access to the abdominal cavity from both a practical and cosmetic point of view. The skin incision on the lower border of the navel about 2/3 of its circumference then the umbilicus is mobilized and completely everted as in umbilical hernia repair. The peritoneal cavity is opened through the vertical incision of the linea alba using the scissors incised vertically along its midline. Hemostasis should be precise to prevent postoperative hematoma. The fascial incision is extended up and down to create a 2 to $3 \mathrm{~cm}$ defect in the linea alba. On the margin of the mini-laparotomy, we place non-absorbable stitches. This allows traction of the abdominal entire during manual SILS port insertion into the abdominal cavity. This incision (mini-laparotomy) later proves to be ideal for relatively large specimen extraction. We prefer Single Incision Laparoscopic Surgery Foam Port (Covidien) as the single umbilical device for introduction of the instruments into the abdominal cavity (Fig. 1). The Covidien SILS port is pushed via the incision starting with the upper more rigid edge (where is the insufflations tube located) and working to the lower softer edge. A flexible videoscope (diameter $10 \mathrm{~mm}$; 0 degrees) is introduced to ensure port position in the abdominal cavity. Pneumoperitoneum was established to $12-14 \mathrm{~mm} \mathrm{Hg}$ and an adequate workspace has been created. Two additional low-profile 5 -mm ports are then placed. It becomes evident that conflicts exist between the hands and instruments of surgeon and assistant. Also the surgeon needs to use his left hand though 


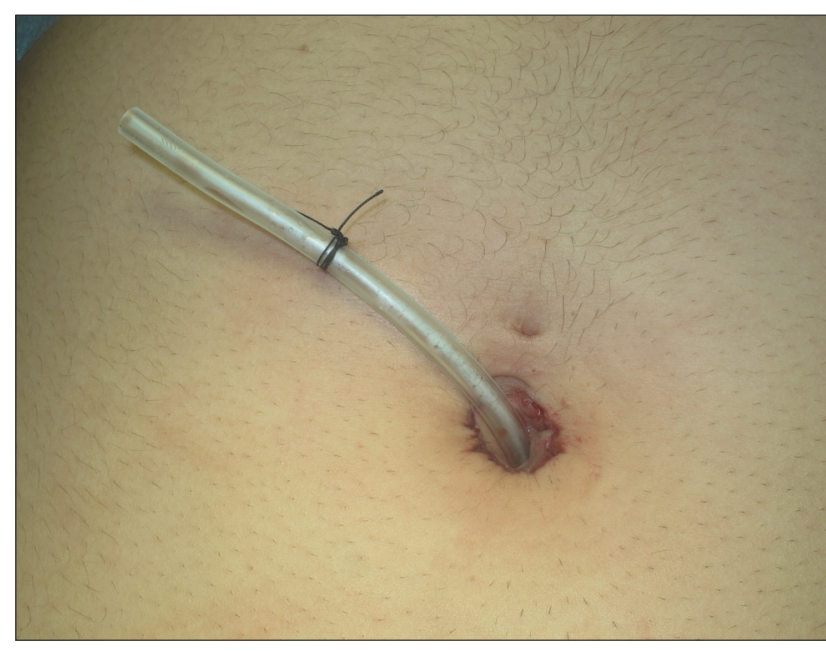

Fig. 7. Peritoneum drain led out through mini-laparotomy.

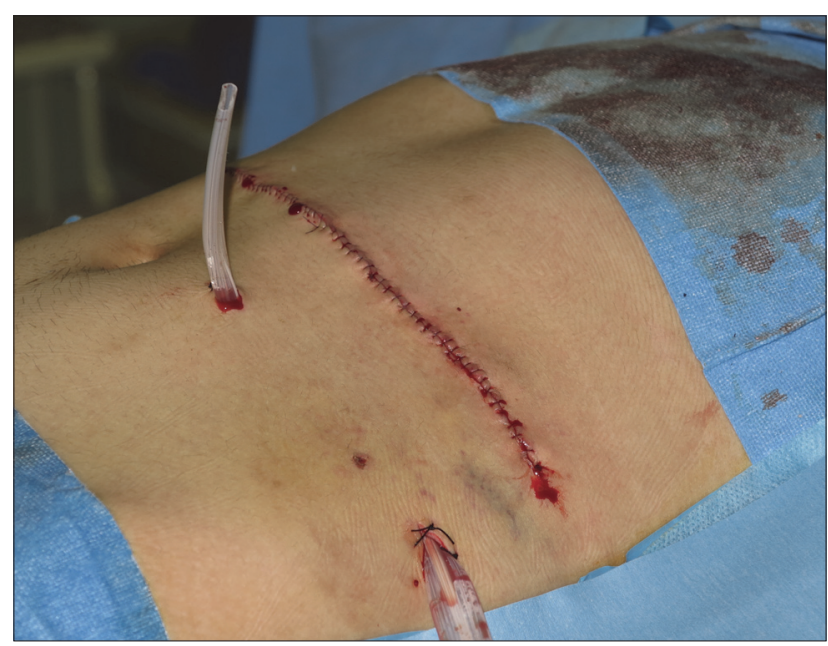

Fig. 8. An example of outcome of routinely used conventional - open surgery, which requires a wide upper abdominal incision.

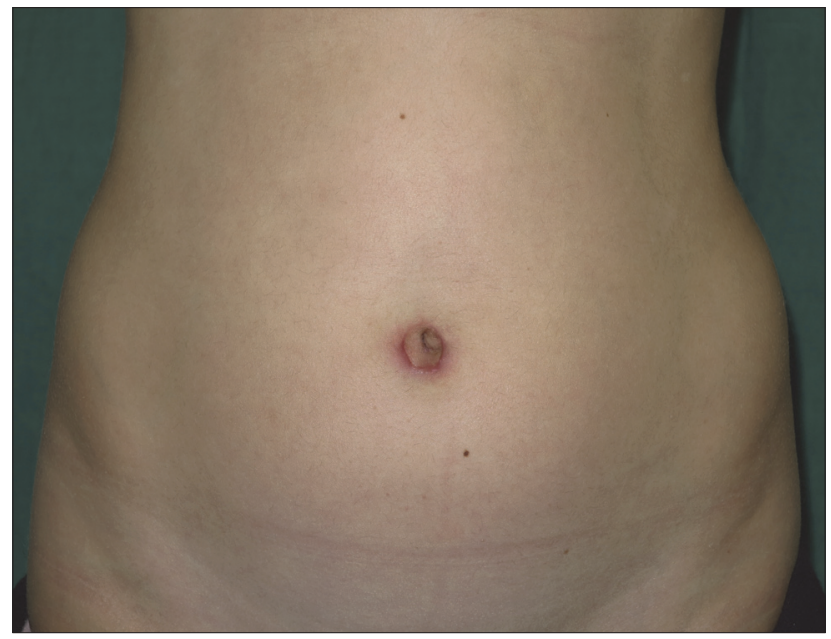

Fig. 9. Scarless surgery - our patient two-months after surgery. A new, promising method for concomitant cholecystectomy and splenectmy. ordinarily he would prefer the right one to clips or to cut as a classic laparoscopy.

\section{SILS cholecystectomy}

The assistant's Grasper is used to elevate the fundus of gallbladder over the liver to ensure optimal exposure of the triangle of Calot. The surgeon retracts the infundibulum of the gallbladder laterally to create appropriate orientation of the cystic and common ducts. Once the anatomy is visualized, cystic duct is doubly clipped on his proximal and distal side and than divided (with Metzenbaum scissors) in the middle of the endoscopic clips (Fig. 3). The cystic artery and cystic duct are clipped separately with a standard 5-mm clip applied. The cystic artery can be as well interrupted by Covidien Ligasure vessel sealing device (Valleylab). Dissection of gallbladder from his liver bed is performed as a normal retrograde cholecystectomy using a monopolar Hook or Harmonic Ace (Ethicon surgery). Hemostasis is controlled with the cautery. Than the gallbladder is put aside over the liver.

\section{SILS total splenectomy}

Turning the patient to the right (semidecubitus position with the left side elevated was achieved by tilting the table during the procedure), so that the spleen fell in to the surgical field. Dissection begins with mobilization of the splenic flexure of the colon and division of the splenocolic ligament and distal polar spleen vessels using the Harmonic Ace (Fig. 4). This allows it to be retracted cephalad. Currently available vessel division tools for the control of the short gastric vessels include the ultrasonic dissector, hemoclips and Ligasure device. After the short gastric vessels are divided, the splenic pedicle may be carefully dissected free superolaterally and anteroposteriorly. For larger hilar vessels (Fig. 5), we applied the Ligasure at 2 points adjacent to each other, and divided only on the seal nearer the spleen. (Contrary to the popular belief, it is not useful to apply energy with the Ligasure at the same site more than once. Moreover, one can risk charring and tearing the vessel with this technique). An endostapler can also be used to divide the vessels in the hilum. The patient had avulsion of a hilar venous branch. An episode of bleeding at the splenic hilum was controlled via SILS. This vessel was controlled with a 5-mm clip applier, and conversion was not necessary. The patient received 1 $\mathrm{U}$ packed red blood cell transfusion. There were no other complications.

After the blood vessels in hilum have been ligated and divided, the completely devascularized spleen was pendent on a small cuff of avascular superior pole splenophrenic ligament, which was then divided.

\section{Finally removing both organs}

To remove the detached organs, a nylon extraction bag was introduced through one of the port sites. The bag was opened within the abdominal cavity and the specimen was introduced into the endo-bag, after internal fragmentation, the bag was closed and exteriorized through the umbilical incision - mini-laparotomy. It is very easy to 
remove the specimen in the endo-bag through the SILS umbilical incision (Fig. 6).

After we removed the gallbladder and the spleen, the umbilical fascial incision was closed. We prefer to close the fascia with interrupted non-absorbable sutures, then the skin is closed with interrupted sutures. The drain was placed through the mini-laparotomy (Fig. 7), the Betadine ${ }^{\circledR}$ unguent and sterile dressing was applied on the umbilicus and the patient was transported to the recovery room.

The main benefit of an SILS approach to splenectony and cholecystectomy appears to be cosmetic because no visible scar results, especial in a case of young girl (compare Fig. 8 and Fig. 9).

\section{Histological evaluation of removed organs}

The fragments of the spleen and gallbladder were after formalin-fixation and paraffin-embedding examined by a pathologist and histologist. In classical histological staining with hematoxylín and eosin, the white pulp of the spleen had a normal appearance, but the splenic red pulp had marked blood congestion in the splenic (Billroth's) cords and we also observed hyperemic blood sinuses (Fig. 10).

The gallbladder mucosal folds were atrophic and the covering epithelium was damaged. The mucosa contained numerous diverticula called Rokitansky-Aschoff sinuses, which may be associated with chronic cholecystitis and cholelitiasis. We observed numerous lymphoid follicles as other morphological signs of chronic cholecystitis and cholelitiasis (Fig. 11).

\section{DISCUSSION}

More than 4,500 reports of SILS procedures have been published ${ }^{14}$ and we may see the same phenomenon

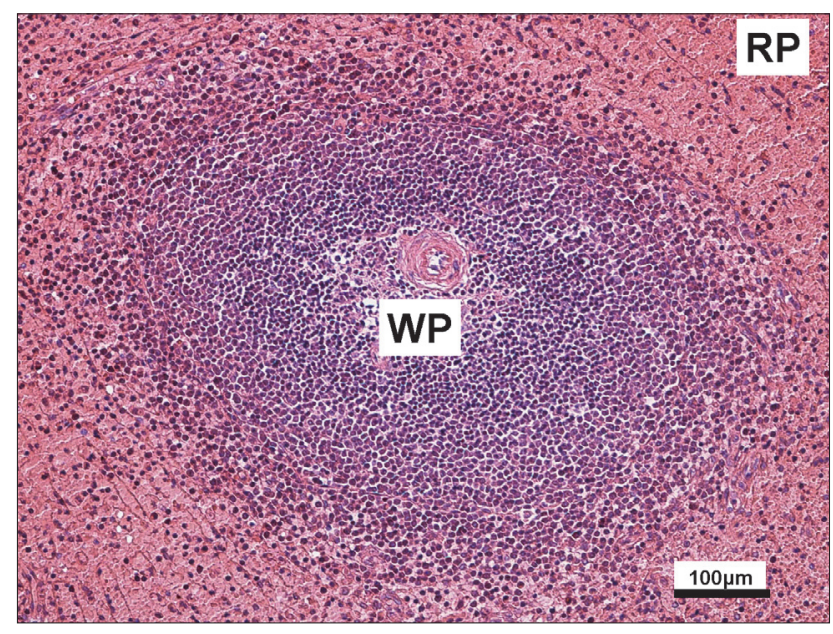

Fig. 10. Microscopic structure of the removed spleen. The white pulp (WP) has normal appearance; red pulp (RP) with marked congestion in splenic (Billroth's) cords and hyperemic blood sinuses (staining with hematoxylin and eosin, Orig. Magn. 100x). occur with the application of single-site laparoscopy. SILS technique was established to facilitate larger specimen retrieval without the need of additional fascial and skin incisions. If multiple procedures are performed at the same time, patients also undergo a solitary hospital admission, preoperative evaluation and anesthesia exposure. Singleincision surgery has been applied to a number of procedures in adults such as appendectomy, cholecystectomy, gastrectomy, adrenalectomy, colorectal procedure, etc. ${ }^{14-19}$.

We have experienced positive results from performing laparoscopic splenectomy and cholecystectomy at one time for treating hereditary spherocytosis that was combined with cholelithiasis. The operation procedure can be difficult to achieve because all instruments come from one direction ${ }^{20}$. Our operation was a rare SILS procedure, when spleen is removed concomitant with the gallbladder (Table 1).

Using instruments of different lengths as well as angled scope prevent clashing between tools and hands of the surgeon and assistant. The use of flexible scope can reduce the possibility of having the camera in-line with the instruments but requires a skilled assistant to operate the telescope. The operative time depends not only on surgeon experience but also on anatomic conditions, the method of blood vessel closing, manner of spleen removal, the size of the spleen and other factors ${ }^{21-23}$. In spite of all these reasons, for experienced laparoscopic surgeons SILS is now easier and there is evidence with appropriate training in rapid decrease in operative times as surgeons acquire experience with the technique. Then overall operative time decreases to a level comparable with standard laparoscopic surgery ${ }^{24,25}$.

Potential postoperative complications with SILS splenectomy and cholecystectomy include wound seroma or ventral hernia. Mobilization of umbilical stem creates a place for eventual fluid collection and infection ${ }^{26}$. This

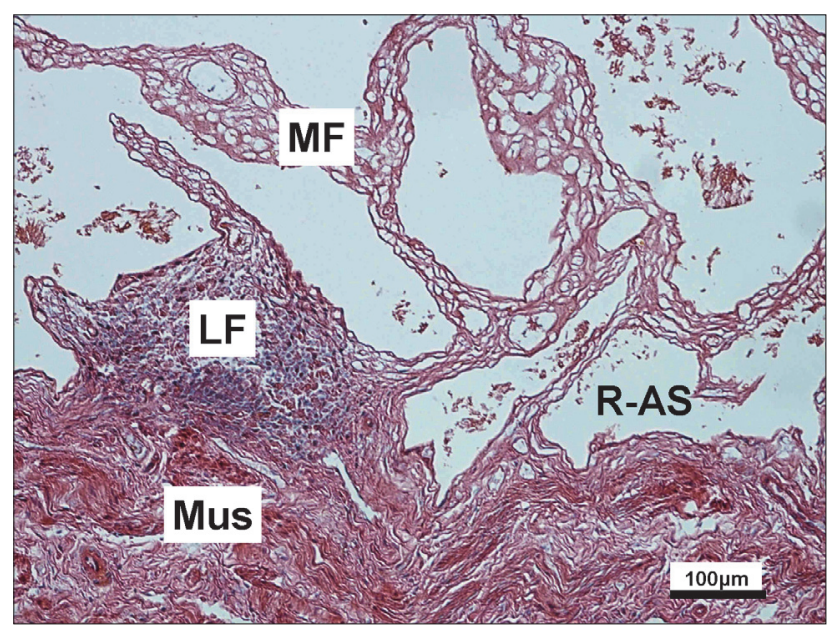

Fig. 11. Section of the removed gallbladders' wall, through mucosa with atrophic mucosal folds (MF) and muscle layer (Mus). Morphologic signs of chronic cholecystitis and cholelitiasis lymphoid follicle (LF) formation within lamina propria and mucosal diverticula called Rokitansky-Aschoff sinuses (R-AS) (staining with hematoxylin and eosin, Orig. Magn. 100x). 
Table 1. Review of published single incision laparoscopic surgical concomitant splenectomy and cholecystectomy procedures.

\begin{tabular}{|c|c|c|c|c|}
\hline Authors & $\begin{array}{l}\text { Regullar } \\
\text { SILS SE+CHE } \\
\text { (number) }\end{array}$ & $\begin{array}{l}\text { SILS SE+CHE } \\
\text { modification } \\
\text { (number) }\end{array}$ & $\begin{array}{l}\text { Mean } \\
\text { oper. time } \\
(\min )\end{array}$ & $\begin{array}{l}\text { Complications } \\
\text { or notes }\end{array}$ \\
\hline Dutta $^{22}$ & 1 & 1 & 165 & $\begin{array}{l}\text { Roticulating instruments } \\
1+\text { spleen was removed through an } 8 \mathrm{~cm} \text { Pfannenstiel } \\
\text { incision. }\end{array}$ \\
\hline Tam et al. ${ }^{29}$ & 1 & 1 & 320 & Conversion to conventional LS \\
\hline Tam et al. ${ }^{30}$ & & 3 & - & $\begin{array}{l}1 \text { Conversion on conventional LS } \\
2 \text { cases with modification of SILS }\end{array}$ \\
\hline Colon et al. ${ }^{31}$ & & 1 & 216 & $\begin{array}{l}\text { Splenic extraction with the modified buldog clamp and hook, } \\
\text { which avoided the need for a fourth trocar. }\end{array}$ \\
\hline Garey et al. ${ }^{28}$ & & 1 & 116 & Modification - one grasper alongside the SILS port \\
\hline \multirow[t]{2}{*}{ Bell et al. ${ }^{14}$} & 2 & 2 & 167 & \\
\hline & Total: 4 & Total: 6 & & \\
\hline
\end{tabular}

CHE - cholecystectomy, SE - splenectomy, LS - laparoscopic

has been reported in several cases of pediatric SILS appendectomy for complicated appendicitis but not in cholecystectomy or splenectomy ${ }^{27,28}$.

Guidelines on hereditary spherocytosis published in 2011 reflect current opinion on the surgical management in children with hereditary spherocytosis. Further potential long term hazards of splenectomy were recognized. So there are recommendations for partial splenectomy. It may be beneficial but needs further follow-up studies ${ }^{11}$. Classically, laparoscopic splenectomy is performed using 4 ports: 10 or $12 \mathrm{~mm}$. Cholecystectomy is performed before splenectomy with or without the additional 1 or 2 ports in right upper quadrant. The main benefit of an SILS approach to splenectomy and cholecystectomy appears to be cosmetic because no visible scar results ${ }^{14}$.

\section{CONCLUSIONS}

Splenectomy is the only effective therapy for hereditary spherocytosis and often it is performed in combination with cholecystectomy in adults. Conventional surgery requires a wide upper abdominal incision for correct exposure of the gallbladder and spleen. Laparoscopic cholecystectomy and splenectomy have been performed safely worldwide. We report our experience with a child who underwent combined SILS splenectomy and cholecystectomy for hereditary spherocytosis.

Our report shows that single-incision splenectomy and cholecystectomy is feasible even in young children and despite the small number of cases in the world, we consider the combined laparoscopic approach safe and effective for the treatment of hereditary spherocytosis.

Laparoscopic splenectomy has become a gold standard in the treatment of spleen disorders related to he- matologic diseases. Increasing laparoscopic surgery experience and improved new vessel sealing equipment have led to a decrease in number of ports in laparoscopic surgery and to operations from one incision.

\section{ACKNOWLEDGEMENTS}

Autorship contributions: LZ, IV: literature search; VC: figures; LZ, IV: manuscript writing; VC, LZ, PK, IV: study design; LZ, IV: final approval.

Conflict of interest statement: None declared.

\section{REFERENCES}

1. Abdullah F, Zhang Y, Camp M, Rossberg MI, Bathurst MA, Colombani PM, Casella JF, Nabaweesi R, Chang DC. Splenectomy in hereditary spherocytosis: Review of 1,657 patients and application of the pediatric quality indicators. Pediatr Blood Cancer 2009;52(7):834-7.

2. Perrotta S, Gallagher PG, Mohandas N. Hereditary spherocytosis. Lancet 2008;372(9647):1411-26.

3. Barcellini W, Bianchi P, Fermo E, Imperiali FG, Marcello AP, Vercellati C, Zaninoni A, Zanella A. Hereditary red cell membrane defects: diagnostic and clinical aspects. Blood Transfus 2011;9(3):274-7.

4. Gulbis B, Eleftheriou A, Angastiniotis M, Ball S, Surrallés J, Castella M, Heimpel H, Hill A, Corrons JL. Epidemiology of rare anaemias in Europe. Adv Exp Med Biol 2010;686:375-96.

5. Biro C, Busikova P, Fujerikova G, El-Hassoun O, Kopaniova A, Caplovicova M, Galfiova P, Sisovsky V, Kopani M, Jakubovsky J. Ironrich complexes in human spleen in hereditary spherocytosis. Bratisl Lek Listy 2012;113(4):214-6.

6. Choi YS, Han HS, Yoon YS, Jang JY, Kim SW, Park YH. Laparoscopic splenectomy plus cholecystectomy for treating hereditary spherocytosis combined with cholelithiasis in siblings. Minim Invasive Ther Allied Technol 2007;16(5):317-8.

7. Holibková A, Machálek L, Laichman S, Zielina P, Mastilová O. Intraperitoneal and extraperitoneal anastomoses of spleen arteries. Sb Lek 2001;102(2):255-63.

8. Steiniger B, Bette M, Schwarzbach $\mathrm{H}$. The open microcirculation 
in human spleens: a three-dimensional approach. J Histochem Cytochem 2011;59(6):639-48.

9. Galfiova P, Pospisilova V, Varga I, Sikuta J, Kiss A, Majesky I, Jakubovsky J, Polak S. Endocrine organs and laser scanning confocal microscopy (LSCM) imaging: vascular bed in human spleen. Endocr Regul 2010;44(4):137-42.

10. Gálfiová P, Varga I, Kopáni M, Michalka P, Michalková J, Jakubovský J, Polák Š. Some possibilities of representing microcirculation in human spleen. Biologia 2009;64(6):1242-6.

11. Bolton-Maggs PH, Langer JC, Iolascon A, Tittensor P, King MJ; General Haematology Task Force of the British Committee for Standards in Haematology. Guidelines for the diagnosis and management of hereditary spherocytosis-2011 update. Br J Haematol 2012;156(1):3749.

12. Sandler A, Winkel G, Kimura K, Soper R. The role of prophylactic cholecystectomy during splenectomy in children with hereditary spherocytosis. J Pediatr Surg 1999;34(7):1077-8.

13. Bruzoni M, Dutta S. Single-site umbilical laparoscopic splenectomy. Semin Pediatr Surg 2011;20(4):212-8.

14. Bell R, Boswell T, Hui T, Su W. Single-incision laparoscopic splenectomy in children. J Pediatr Surg 2012;47(5):898-903.

15. Ahmed I, Ciancio F, Ferrara V, Jorgensen LN, Mann O, Morales-Conde $\mathrm{S}$, Paraskeva P, Vestweber B, Weiss H. Current status of single-incision laparoscopic surgery: European experts' views. Surg Laparosc Endosc Percutan Tech 2012;22(3):194-9.

16. Fung AK, Aly EH. Systematic review of single-incision laparoscopic colonic surgery. Br J Surg 2012;99(10):1353-64.

17. Kim BS, Kim KC, Choi YB. A comparison between single-incision and conventional laparoscopic cholecystectomy. J Laparoendosc Adv Surg Tech A 2012;22(5):443-7.

18. Garcia-Henriquez N, Shah SR, Kane TD. Single-incision laparoscopic cholecystectomy in children using standard straight instruments: a surgeon's early experience. J Laparoendosc Adv Surg Tech A 2011;21(6):555-9.

19. Goo TT, Agarwal A, Goel R, Tan CT, Lomanto D, Cheah WK. Singleport access adrenalectomy: our initial experience. J Laparoendosc Adv Surg Tech A 2011;21(9):815-9.
20. Esposito C. One-trocar appendectomy in pediatric surgery. Surg Endosc 1998;12:177-8.

21. Ponsky LE, Cherullo EE, Sawyer M, Hartke D. Single access site laparoscopic radical nephrectomy: initial clinical experience. J Endourol 2008;22(4):663-6.

22. Dutta S. Early experience with single incision laparoscopic surgery: eliminating the scar from abdominal operations. J Pediatr Surg 2009:44(9):1741-5.

23. Patkowski D, Chrzan R, Wrobel G, Sokol A, Dobaczewski G, Apoznanski W, Dorobis U, Czernik J. Laparoscopic splenectomy in children: experience in a single institution. . J Laparoendosc Adv Surg Tech A 2007;17(2):230-4.

24. Shussman N, Schlager A, Elazary R, Khalaileh A, Keidar A, Talamini M, Horgan S, Rivkind Al, Mintz Y. Single-incision laparoscopic cholecystectomy: lessons learned for success. Surg Endosc 2011;25(2):404-7.

25. Ahmed I, Paraskeva P. A clinical review of single-incision laparoscopic surgery. Surgeon 2011;9(6):341-51.

26. Rescorla FJ, West KW, Engum SA, Grosfeld JL. Laparoscopic splenic procedures in children: experience in 231 children. Ann Surg 2007;246(4):683-7.

27. Ponsky TA, Diluciano J, Chwals W, Parry R, Boulanger S. Early experience with single-port laparoscopic surgery in children. $J$ Laparoendosc Adv Surg Tech A 2009;19(4):551-3.

28. Garey CL, Laituri CA, Ostlie DJ, Snyder CL, Andrews WS, Holcomb GW, St Peter SD. Single-incision laparoscopic surgery in children: initial single-center experience. J Pediatr Surg 2011;46(5):904-7.

29. Tam YH, Lee KH, Sihoe JD, Chan KW, Cheung ST, Pang KK. Initial experience in children using conventional laparoscopic instruments in single-incision laparoscopic surgery. J Pediatr Surg 2010:45(12):2381-5.

30. Tam YH, Lee KH, Chan KW, Sihoe JD, Cheung ST, Pang KK. Technical report on the initial cases of single-incision laparoscopic combined cholecystectomy and splenectomy in children, using conventional instruments. Surg Innov 2010;17(3):264-8.

31. Colon MJ, Telem D, Chan E, Midulla P, Divino C, Chin EH. Laparoendoscopic single site (LESS) splenectomy with a conventional laparoscope and instruments. JSLS 2011;15(3):384-6. 